\title{
PENGARUH WAKTU PEMBERIAN DAN KONSENTRASI PACLOBUTRAZOL TERHADAP PERLAMBATAN PERTUMBUHAN TREMBESI (Albizia saman Jacq)
}

\section{EFFECT OF TIME AND CONCENTRATION OF PACLOBUTRAZOL ON GROWTH RETARDATION OF RAIN TREE (Albizia saman Jacq)}

\author{
F. Fathurrahman*, Sri Mulyani dan Rico Prasetyo Candra \\ Program Studi Agroteknologi, Fakultas Pertanian, Universitas Islam Riau, Indonesia \\ Email: fathur@agr.uir.ac.id \\ * Corresponding Author, Diterima: 4 Mei 2021, Direvisi: 1 Des. 2021, Disetujui: 6 Des. 2021
}

\begin{abstract}
The aims of this study was to determine the effect of spraying time and concentration of paclobutrazol on the growth rain tree seedlings (Albizia saman, Jacq). Rain tree has advantage by absorbing $\mathrm{CO}_{2}$ from the atmosphere in large quantities. The disadvantage is that size of the tree is large so it needs to be done to slowly or inhibit growth can be planted in small narrow garden. The experiment was carried out in the experimental farm Faculty of Agriculture, Universitas Islam Riau, Air Dingin Village, Bukit Raya District, Pekanbaru Riau Indonesia from March to June 2020. This research has been carried out experimentally using a completely randomized design consisting of two factors and three replications. The first factor is spraying time which is divided into three levels. The second one is the concentration of paclobutrazol, consisting of four levels. The results showed that could slow plant height up to $54.67 \%$. Increase in the size diameter stem at 50 days and 75 days with concentration $150 \mathrm{ppm}$ with stem diameter of $0.94 \mathrm{~cm}$ and 0.92 $\mathrm{cm}$, respectively. Emphasis on the number primary branches at 50 days treatment and a concentration of $150 \mathrm{ppm}$ which only produced 17.58 branches. The number of leaves also decreased by 72.83 leaves compared to the control, which was 91.92 leaves. The chlorophyll content showed the highest diversity in the control.
\end{abstract}

Keywords: Albizia saman, concentration growth, paclobutrazol. time.

\begin{abstract}
ABSTRAK
Tujuan penelitian ini untuk mengetahui pengaruh waktu penyemprotan dan konsentrasi paclobutrazol terhadap pertumbuhan bibit trembesi (Albizia saman, Jacq). Trembesi adalah tanaman yang memiliki kelebihan dalam menyerap $\mathrm{CO}_{2}$ dari atmosfera dalam kuantitas yang besar. Kelemahannya, ukuran pohon besar sehingga perlu dilakukan untuk memperlambat atau menghambat pertumbuhannya agar dapat ditanam di pekarangan yang sempit. Eksperimen telah dilakukan di kebun percobaan Fakultas Pertanian Universitas Islam Riau, Kelurahan Air Dingin, Kecamatan Bukit Raya, Pekanbaru Riau Indonesia mulai Maret sampai Juni 2020. Penelitian menggunakan Rancangan Acak Lengkap secara faktorial terdiri dari dua faktor dan tiga ulangan. Faktor pertama waktu penyemprotan, terdiri dari 3 taraf. Faktor kedua konsentrasi paclobutrazol, terdiri dari 4 taraf. Uji lanjut yang digunakan untuk parameter morfologi adalah BNJ pada $p<0,05$ dan parameter fisiologi adalah DMRT pada $p<0,05$. Hasil penelitian menunjukkan dapat memperlambat tinggi tanaman sampai $54,67 \%$. Peningkatan ukuran diameter batang tanaman pada waktu penyemptotan 50 HST dan 75 HST dengan pemberian paclobutrazol $150 \mathrm{ppm}$ masing masing $0,94 \mathrm{~cm}$ dan $0,92 \mathrm{~cm}$. Penekanan jumlah cabang primer pada waktu penyemptotan 50 HST dengan perlakuan konsentrasi paclobutrazol $150 \mathrm{ppm}$ hanya menghasilkan 17,58 cabang. Jumlah daun juga menurun 72,83 helai berbanding kontrol yaitu 91,92 helai. Untuk kandungan klorofil menunjukkan keragaman tertinggi pada kontrol.
\end{abstract}

Kata kunci: Albizia saman, konsentrasi pertumbuhan, paclobutrazol, waktu. 


\section{PENDAHULUAN}

Peningkatan suhu saat ini penyebabnya adalah karena adanya perubahan iklim. Beberapa studi menemukan bahwa setiap kenaikan suhu udara $2^{\circ} \mathrm{C}$, akan menurunkan produksi pertanian nanti pada tahun 2050. Peningkatan karbon dioksida diantaranya disebabkan oleh berbagai aktivitas manusia yang berkaitan dengan pencemaran lingkungan. Peningkatan terus menerus suhu di permukaan bumi disebabkan oleh gas karbon dioksida $\left(\mathrm{CO}_{2}\right)$ sangat serius mengingat gas ini merupakan salah satu gas rumah kaca terbanyak di udara dan secara tidak langsung mendatangkan efekyang berbahaya bagi kemandirian organismehidup.

Langkah untuk menangani masalah peningkatan konsentrasi $\mathrm{CO}_{2}$ dengan mitigasi konsentrasi $\mathrm{CO}_{2}$. Komitmen Indonesia tersebut diperkuat melalui dokumen Nationally Determined Contribution (NDC) pada bulan November 2016 dengan ditetapkannya target unconditional sebesar $29 \%$ dan target sampai dengan $41 \%$ tahun 2030 . Secara nasional, target penurunan emisi pada tahun 2030 adalah sebesar 834 juta ton $\mathrm{CO}_{2}$ (Direktorat Jenderal Pengendalian Perubahan Iklim, 2022). Untuk memenuhi target tersebut, secara nasional telah dilakukan berbagai aksi mitigasi pada semua sektor termasuk usaha reboisasi hutan yang rusak dan penghijauan lahan kosong. Namun belum diketahui jenis spesies tanaman yang menyerap $\mathrm{CO}_{2}$ yang tinggi.

Usaha yang dapat mengurangi dampak peningkatan suhu diantaranya penanaman tanaman yang dapat menyerap $\mathrm{CO}_{2}$ lebih tinggi contohnya penanaman trembesi (Fathurrahman et al. 2016). Satu batang tanaman Trembesi (Albizia saman Jacq) yang berumur di atas 10 tahun mampu menyerap $\mathrm{CO}_{2} 28.488,39 \mathrm{~kg}$. Trembesi dapat tumbuh tinggi hingga mencapai ketinggian 25 meter, dengan diameter batang mencapai 2 meter dan diameter kanopi mencapai 30 meter.

Trembesi kurang sesuai ditanam di pekarangan rumah, karena jika telah tumbuh menjadi pohon yang besar, akarnya dapat merusak pondasi rumah. Namun demikian, tumbuhan trembesi ini menjadi populer sebagai tanaman peneduh dan penghasil oksigen. Oleh karena itu perlu dilakukan penelitian bagaimana memperlambat pertumbuhan trembesi agar dapat ditanam di pekarangan yang sempit namun menghasilkan daun yang banyak untuk proses fotosintesis dalam penyerapan $\mathrm{CO}_{2}$.

Zat pengatur tumbuh yang umum digunakan adalah Paclobutrazol (PBZ). Pakloburazol merupakan salah satu retardan yang bila diberikan pada tanaman yang responsif dapat menghambat perpanjangan sel pada sistem sub apikal, mengurangi laju perpanjangan batang tanpa mempengaruhi pertumbuhan dan perkembangan daun (Tumewu, et al. 2012). Paclobutrazol dikenal sebagai penghambat pertumbuhan dan penghambat penghasilan biosintesis phytohormon giberelin.

Tujuan penelitian ini adalah untuk mengetahui interaksi pengaruh waktu penyemprotan dan konsentrasi PBZ terhadap penghambatan pertumbuhan dan fisiologi bibit trembesi sehingga populasinya meningkat dan dapat ditanam secara meluas agar terjadi peningkatan penyerapan $\mathrm{CO}_{2}$.

\section{BAHAN DAN METODE}

Bahan yang diperlukan dalam penelitian ini adalah benih Trembesi, paclobutrazol, tanah lapisan atas, polybag ukuran $30 \mathrm{~cm} \times 35 \mathrm{~cm}$, pupuk kandang, pupuk NPK, decis, furadan. Alat yang digunakan dalam penelitian ini adalah meteran, kamera dan Klorofil Meter Portabel SPAD-502. Eksperimen telah dilakukan di kebun percobaan Fakultas Pertanian Universitas Islam Riau, Kelurahan Air Dingin, Kecamatan Bukit Raya, Pekanbaru Riau Indonesia. Kegiatan penelitian dilaksanakan 4 bulan terhitung bulan Maret - Juni 2020. Jenis tanah yang digunakan untuk media tanam dalam polybag adalah tanah ultisol dengan $\mathrm{pH}$ 5.6. Penelitian ini menggunakan Rancangan Acak Lengkap (RAL) Faktorial yang terdiri dari dua faktor. Faktor pertama adalah waktu penyemprotan $(\mathrm{T})$ terdiri dari tiga taraf dan faktor ke dua konsentrasi Paclobutrazol (PBZ) (P) yang terdiri dari 4 taraf sehingga diperoleh 12 kombinasi perlakuan dengan 3 kali ulangan maka ada 36 unit percobaan. Masing - masing unit terdiri dari 4 tanaman per plot dan 2 tanaman dijadikan sampel pengamatan sehingga total 144 tanaman.

Faktor perlakuan disusun sebagai berikut: Faktor pertama waktu penyemprotan (T) terdiri dari tiga taraf yaitu $\mathrm{T} 1=25$ hari setelah tanam $($ HST), T2 $=50$ HST dan T3 $=75$ HST. Faktor kedua konsentrasi Paclobutrazol (PBZ) (P), meliputi empat taraf yaitu $\mathrm{P} 0=$ kontrol, $\mathrm{P} 1=75$ ppm, $\mathrm{P} 2=150 \mathrm{ppm}$ dan $\mathrm{P} 3=225 \mathrm{ppm}$. Parameter pengamatan yang diamati tinggi tanaman $(\mathrm{cm})$, diameter batang, jumlah cabang primer, jumlah daun dan kadar klorofil. Semua data pengamatan dianalisis menggunakan analisis statistik dengan analisis ragam dua arah. Bila $\mathrm{F}$ tabel yang diperoleh lebih kecil dari $\mathrm{F}$ hitung, maka uji lanjut Beda 
Nyata Jujur (BNJ) pada $\mathrm{p}<0,05$ menggunakan perangkat lunak SAS 9.1.3 untuk pengamatan marfologi dan kandungan klorofil.

\section{HASIL DAN PEMBAHASAN}

\subsection{Tinggi Tanaman}

Data hasil pengamatan tinggi tanaman trembesi setelah dianalisis ragam menunjukkan bahwa interaksi dan utama perlakuan waktu penyemprotan dan konsentrasi paclobutrazol (PBZ) berpengaruh nyata terhadap tinggi tanaman trembesi. Rata-rata pengamatan tinggi tanaman setelah diuji lanjut $\mathrm{BNJ} \mathrm{p}<0,05$ dapat dilihat pada Tabel 1.

Tabel 1 menunjukan bahwa interaksi perlakuan dapat menekan tinggi tanaman adalah pada waktu penyemprotan tanaman 50 HST dan konsentrasi PBZ 75 ppm dan 225 ppm masing masing dengan tinggi $42,43 \mathrm{~cm}$ dan $43,83 \mathrm{~cm}$ serta dapat menekan pertumbuhan tinggi dibandingkan kontrol sampai $54,67 \%$. Selanjutnya secara pengaruh utama pada waktu penyemprotan tanaman hasil terbaik adalah pada 50 HST dan 75 HST. Sedangkan pengaruh utama pada perlakuan konsentrasi paclobutrazol dapat menekan pertumbuhan sampai 46,62 cm. Hal ini membuktikan bahwa penyemprotan pada tanaman dengan umur yang berbeda dan konsentrasi yang berbeda dapat menekan pertumbuhan tinggi tanaman trembesi.

Dari data pengamatan ternyata paclobutrazol dapat menghambat sintesis giberelin pada tanaman trembesi dengan cara menghambat proses oksidasi kauren menjadi asam kaurenat. Penelitian yang dilakukan oleh Jungklang et al. (2017) menunjukan pemberian PBZ dengan konsentrasi 1.500 ppm menghambat tinggi tanaman tulip Siam. Selanjutnya pengaruh PBZ terhadap pertumbuhan vegetatif dan generatif tanaman sedap malam responnya masih linear sampai 375 ppm. PBZ akan menghambat biosintesis giberelin pada meristem sub apikal, yang selanjutnya akan menyebabkan penurunan laju pembelahan sel sehingga menghambat pertumbuhan vegetatif dan secara tidak langsung akan mengalihkan fotosintat ke pertumbuhan reproduktif yang diperlukan untuk membentuk bunga, buah dan perkembangan buahn (Salisbury \& Ross, 1992).

Rosmanita (2008) menyatakan bahwa PBZ konsentrasi $600 \mathrm{ppm}$ menghasilkan ruas batang lebih pendek dan meningkatkan jumlah tunas berbunga melati (Jasminum sambac). Penelitian lainnya oleh Nasrullah et al. (2012), PBZ dengan konsentrasi $500 \mathrm{ppm}$ dapat mengakibatkan batang tanaman bugenvil lebih pendek konsentrasi 250 dan 500 ppm dapat menghasilkan cluster dan total bunga terbanyak. Selanjutnya Santiasrini (2009) pemberian PBZ efektif menekan tinggi batang tanaman pelargonium yang diaplikasikan secara semprotan pada konsentrasi $80 \mathrm{ppm}$. Penekanan pertumbuhan tinggi tanaman tahunan juga terjadi pada cengkeh seperti yang dilaporkan oleh Runtunuwu et al. (2011), penyemprotan PBZ dengan $25 \mathrm{ppm}-100 \mathrm{ppm}$, semakin tinggi konsentrasi PBZ, makin pendek panjang ruas tunas apikal yang dihasilkan.

Menurut Bonaventura et al. (2013) pengaruh waktu penyemprotan 47 hari setelah tanam dengan PBZ untuk menghambat tinggi tanaman. Karena cara kerjanya menghambat sintesis giberelin di dalam tubuh tanaman, dengan dihambatnya produksi giberelin maka sel terus membelah tapi sel - sel tersebut tidak memanjang.

\subsection{Diameter Batang}

Hasil pengamatan diameter trembesi setelah dianalisis ragam menunjukkan bahwa interaksi dan utama perlakuan waktu penyepotan dan konsentrasi paclobutrazol (PBZ) berpengaruh nyata terhadap

Tabel 1. Rata-rata Tinggi Tanaman $(\mathrm{cm})$ Trembesi pada Perlakuan Waktu Penyemprotan dan Konsentrasi PBZ pada Umur 156 HST.

\begin{tabular}{clcccc}
\hline Waktu & \multicolumn{3}{c}{ Konsentrasi Paclobutrazol (ppm) } & \multirow{2}{*}{ Rata-rata } \\
\cline { 2 - 4 } Penyempotan (HST) & $0(\mathrm{~K} 0)$ & $75(\mathrm{~K} 1)$ & $150(\mathrm{~K} 2)$ & $225(\mathrm{~K} 3)$ & \\
\hline $25(\mathrm{~W} 1)$ & $77,60 \mathrm{e}$ & $58,00 \mathrm{de}$ & $49,57 \mathrm{de}$ & $51,57 \mathrm{de}$ & $59,18 \mathrm{~b}$ \\
$50(\mathrm{~W} 2)$ & $67,33 \mathrm{e}$ & $50,77 \mathrm{de}$ & $42,43 \mathrm{a}$ & $43,83 \mathrm{ab}$ & $51,09 \mathrm{a}$ \\
$75(\mathrm{~W} 3)$ & $61,67 \mathrm{e}$ & $48,45 \mathrm{cde}$ & $47,85 \mathrm{bcd}$ & $46,35 \mathrm{bc}$ & $51,08 \mathrm{a}$ \\
\hline Rata-rata & $68,87 \mathrm{c}$ & $52,41 \mathrm{c}$ & $46,62 \mathrm{a}$ & $47,25 \mathrm{~b}$ & \\
\hline KK=6,80\% & BNJ W $=4,30$ & \multicolumn{2}{c}{ BNJ K $=4,12$} & BNJ WK $=10,03$ & \\
\hline
\end{tabular}

Keterangan : Angka-angka pada kolom dan baris yang diikuti oleh huruf kecil yang sama tidak berbeda nyata menurut uji beda nyata jujur $\mathrm{BNJ}$ pada $\mathrm{p}<0,05$. 
diameter trembesi. Rata-rata pengamatan diameter tanaman setelah diuji lanjut BNJ pada $\mathrm{p}<0,05$ dapat dilihat pada Tabel 2 .

Berdasarkan Tabel 2 menunjukan bahwa interaksi perlakuan dapat meningkatkan diameter tanaman adalah pada waktu penyemprotan tanaman 50 HST dan 75 HST serta konsentrasi PBZ 150 ppm masing masing dengan diameter batang $0,94 \mathrm{~cm}$ dan $0,92 \mathrm{~cm}$. Peningkatan diameter batang dibandingkan kontrol sampai $15 \mathrm{~mm}$. Selanjutnya pengaruh utama pada waktu penyemprotan terbaik adalah pada 50 HST dan 75 HST. Sedangkan pengaruh utama pada perlakuan konsentrasi PBZ dapat meningkatkan pertumbuhan tertinggi pada perlakuan PBZ 150 ppm. Hal ini membuktikan bahwa penyemprotan pada tanaman dengan umur yang berbeda dan konsentrasi yang berbeda dapat meningkatkan pertumbuhan diameter trembesi.

Penghambatan tinggi tanaman trembesi oleh PBZ telah mengarahkan peningkatan pertumbuhan diameter batang trembesi. Penelitian Wirdayanto (2011), melaporkan bahwa penambahan PBZ dapat menekan pertumbuhan tanaman stek jambu sehingga diameter tanaman bertambah besar. Efek PBZ pada pertumbuhan vegetatif adalah memperpendek ruas sehingga menghambat pertumbuhan tinggi tanaman, dan memperbesar diameter batang tanaman (Ardigusa dan Sukma, 2015). PBZ dapat menghambat pertumbuhan sel meristem apikal sehingga menyebabkan inisiasi kambium pada sel parenkim meningkat, proses inisiasi sel parenkim meningkat maka yang terjadi adalah peningkatan diameter batang tanaman. Penelitian Rugayah et al. (2020), pemberian PBZ konsentrasi tertinggi $375 \mathrm{ppm}$ dapat menghasilkan lingkar batang bunga sedap malam tertinggi. Pertumbuhan primer pada batang dan akar, inisiasi prokambium yang berasal dari meristem apikal menghasilkan xylem primer dan floem primer. Inisiasi kambium vaskular, yang berasal dari prokambium dan sel parenkim lainnya ketika tanaman mengalami pertumbuhan sekunder, memberikan pertumbuhan xilem sekunder, yang umumnya disebut kayu, dan floem sekunder.

\subsection{Jumlah Cabang Primer}

Analisis ragam menunjukkan bahwa interaksi dan perlakuan waktu penyepotan dan konsentrasi PBZ berpengaruh nyata terhadap jumlah cabang primer trembesi. Rata-rata pengamatan jumlah cabang primer setelah diuji lanjut $\mathrm{BNJ} p<0,05$ dapat dilihat pada Tabel 3 .

Tabel 2. Rata-rata Diameter Batang (cm) Trembesi dengan Perlakuan Waktu Penyemprotan dan Konsentrasi PBZ.

\begin{tabular}{cllllc}
\hline Waktu & \multicolumn{4}{c}{ Konsentrasi Paclobutrazol $(\mathrm{ppm})$} & \multirow{2}{*}{ Rata-rata } \\
\cline { 2 - 5 } Penyempotan $(\mathrm{HST})$ & $0(\mathrm{~K} 0)$ & $75(\mathrm{~K} 1)$ & $150(\mathrm{~K} 2)$ & $225(\mathrm{~K} 3)$ & \\
\hline $25(\mathrm{~W} 1)$ & $0,79 \mathrm{f}$ & $0,86 \mathrm{abcde}$ & $0,89 \mathrm{abcd}$ & $0,82 \mathrm{ef}$ & $0,84 \mathrm{~b}$ \\
$50(\mathrm{~W} 2)$ & $0,84 \mathrm{def}$ & $0,86 \mathrm{bcde}$ & $0,94 \mathrm{a}$ & $0,90 \mathrm{abc}$ & $0,89 \mathrm{a}$ \\
$75(\mathrm{~W} 3)$ & $0,85 \mathrm{cdef}$ & $0,85 \mathrm{cdef}$ & $0,92 \mathrm{ab}$ & $0,88 \mathrm{abcde}$ & $0,88 \mathrm{a}$ \\
\hline Rata-rata & $0,82 \mathrm{c}$ & $0,86 \mathrm{~b}$ & $0,92 \mathrm{a}$ & $0,87 \mathrm{~b}$ & \\
\hline KK=2,58\% & BNJ W $=0,03$ & \multicolumn{1}{c}{ BNJ K $=0,03$} & BNJ WK $=0,06$ & \\
\hline
\end{tabular}

Keterangan : Angka-angka pada kolom dan baris yang diikuti oleh huruf kecil yang sama tidak berbeda nyata menurut uji beda nyata jujur BNJ pada $\mathrm{p}<0,05$.

Tabel 3. Rata-rata Jumlah Cabang Primer Trembesi dengan Perlakuan Waktu Penyemprotan dan Konsentrasi PBZ.

\begin{tabular}{cccccc}
\hline Waktu & \multicolumn{3}{c}{ Konsentrasi Paclobutrazol (ppm) } & \multirow{2}{*}{ Rata-rata } \\
\cline { 2 - 4 } Penyempotan $(\mathrm{HST})$ & $0(\mathrm{~K} 0)$ & $75(\mathrm{~K} 1)$ & $150(\mathrm{~K} 2)$ & $225(\mathrm{~K} 3)$ & $20,69 \mathrm{~b}$ \\
\hline $25(\mathrm{~W} 1)$ & $23,67 \mathrm{~b}$ & $21,03 \mathrm{~b}$ & $18,70 \mathrm{a}$ & $19,34 \mathrm{~b}$ & $19,24 \mathrm{~b}$ \\
$50(\mathrm{~W} 2)$ & $20,83 \mathrm{~b}$ & $19,38 \mathrm{~b}$ & $17,58 \mathrm{a}$ & $19,17 \mathrm{~b}$ & $18,97 \mathrm{a}$ \\
\hline $75(\mathrm{~W} 3)$ & $19,17 \mathrm{~b}$ & $19,33 \mathrm{~b}$ & $19,12 \mathrm{ab}$ & $18,25 \mathrm{ab}$ & $18,92 \mathrm{ab}$ \\
\hline Rata-rata & $21,22 \mathrm{~b}$ & $19,92 \mathrm{~b}$ & $18,47 \mathrm{a}$ & \multicolumn{2}{c}{ BNJ WK $=3,37$} \\
\hline KK=6,25\% & BNJ W $=1,44$ & \multicolumn{2}{c}{ BNJ K $=1,38$} & \\
\hline
\end{tabular}

Keterangan : Angka-angka pada kolom dan baris yang diikuti oleh huruf kecil yang sama tidak berbeda nyata menurut uji beda nyata jujur BNJ pada $\mathrm{p}<0,05$. 
Data pada Tabel 3 menunjukkan bahwa interaksi perlakuan dapat menghambat pertumbuhan cabang primer trembesi pada waktu penyemprotan tanaman $25 \mathrm{HST}, 50 \mathrm{HST}$ dan 75 HST serta konsentrasi PBZ 150 ppm masing masing dengan jumlah cabang primer 18,70 cabang, 17,58 cabang dan 19,12 cabang. Jumlah cabang primer perlakuan lebih sedikit dengan selisih tertinggi 6,06 cabang dibandingkan dengan kontrol. Selanjutnya pengaruh utama waktu penyemprotan tanaman hasil terbaik adalah pada 75 HST. Sedangkan pengaruh utama pada perlakuan konsentrasi PBZ dapat menekan pertumbuhan jumlah cabang pada perlakuan PBZ 150 ppm. Hal ini membuktikan bahwa penyemprotan pada tanaman dengan umur yang berbeda dan konsentrasi yang berbeda dapat menghambat pertumbuhan jumlah cabang primer trembesi.

Zat pengatur tumbuh ini dapat menekan pertumbuhan vegetatif tanaman, serta menghambat sintesis giberelin yang berfungsi dalam pemanjangan sel (Salisbury dan Ross,1995). Pengaruh penggunaan zat pengatur tumbuh PBZ signifikan pada batang, tangkai daun, jaringan tangkai bunga, serta menyebabkan daun semakin tebal dengan warna yang lebih gelap (Lattimer, 1988).

PBZ menghambat biosintesis giberelin pada meristem sub apikal, yang selanjutnya akan menyebabkan penurunan laju pembelahan sel sehingga menghambat pertumbuhan vegetatif dan mengalihkan fotosintat ke pertumbuhan reproduktif yang diperlukan untuk membentuk bunga, buah dan perkembangan buah (Salisbury \& Ross, 1992). Respon berbagai macam tanaman yang terdiri dari tanaman dan hortikultura dan tanaman perkebunan terhadap pemberian PBZ berbeda-beda. Sebagian besar responnya bagi tanaman menghambat pertumbuhan sebaliknya terjadi juga pada beberapa tanaman budidaya memacu pertumbuhan.

\subsection{Jumlah Daun}

Hasil pengamatan jumlah daun trembesi setelah dianalisis ragam menunjukkan bahwa interaksi dan utama perlakuan waktu penyepotan dan konsentrasi PBZ berpengaruh nyata terhadap jumlah daun trembesi. Rata-rata pengamatan jumlah daun setelah diuji lanjut $\mathrm{BNJ} \mathrm{p}<0,05$ dapat dilihat pada Tabel 4.

Data pada Tabel 4 menunjukkan bahwa interaksi perlakuan dapat menghambat pertumbuhan jumlah daun trembesi pada saat penyemprotan tanaman $25 \mathrm{HST}, 50 \mathrm{HST}$ dan 75 HST serta konsentrasi PBZ 150 ppm masing masing dengan jumlah jumlah daun trembesi 72,83 daun dan 76,60 daun. Jumlah daun trembesi perlakuan lebih sedikit dengan selisih tertinggi yaitu 19,09 daun dibandingkan dengan kontrol. Selanjutnya pengaruh utama waktu penyemprotan tanaman hasil terbaik adalah pada 50 HST. Sedangkan pengaruh utama pada perlakuan konsentrasi PBZ dapat menekan pertumbuhan jumlah cabang pada perlakuan PBZ 150 ppm. Hal ini membuktikan bahwa penyemprotan pada tanaman dengan umur yang berbeda dan konsentrasi yang berbeda dapat menghambat pertumbuhan jumlah daun trembesi.

PBZ dapat menghambat tinggi tanaman namun tidak berpengaruh nyata terhadap jumlah daun tanaman trembesi. Hal ini sesuai dengan Harpitaningrum, dkk. (2014) menyatakan bahwa peningkatan pemberian konsentrasi PBZ berpengaruh nyata dalam menekan jumlah daun sebab PBZ menghambat pertumbuhan vegetatif tanaman karena pertumbuhan tinggi tanaman terhambat, maka pertumbuhan jumlah daun juga akan semakin sedikit. Terhambatnya jumlah daun maka secara fisiologi juga menyebabkan proses fotosintesis lebih sedikit sehingga akumulasi hasil

Tabel 4. Rata-rata Jumlah Daun Trembesi dengan Perlakuan Waktu Penyemprotan dan Konsentrasi PBZ.

\begin{tabular}{cccccc}
\hline Waktu & \multicolumn{4}{c}{ Konsentrasi Paclobutrazol (ppm) } & \multirow{2}{*}{ Rata-rata } \\
\cline { 2 - 5 } Penyempotan (HST) & $0(\mathrm{~K} 0)$ & $75(\mathrm{~K} 1)$ & $150(\mathrm{~K} 2)$ & $225(\mathrm{~K} 3)$ & \\
\hline $25(\mathrm{~W} 1)$ & 91,92 & 85,42 & 85,83 & 79,67 & $85,71 \mathrm{~b}$ \\
$50(\mathrm{~W} 2)$ & 89,67 & 81,17 & 72,83 & 77,50 & $80,29 \mathrm{a}$ \\
$75(\mathrm{~W} 3)$ & 84,33 & 80,83 & 76,60 & 77,25 & $79,73 \mathrm{a}$ \\
\hline Rata-rata & $88,64 \mathrm{~b}$ & $82,47 \mathrm{~b}$ & $78,39 \mathrm{ab}$ & $78,14 \mathrm{a}$ & \\
\hline KK=6,46\% & BNJ W $=3,27$ & BNJ K $=3,13$ & BNJ WK $=7,62$ & \\
\hline
\end{tabular}

Keterangan : Angka-angka pada kolom dan baris yang diikuti oleh huruf kecil yang sama tidak berbeda nyata menurut uji beda nyata jujur BNJ pada $\mathrm{p}<0,05$. 
fotosintesis yang dapat dirubah dalam bentuk bahan primer dan skunder yang lebih sederhana dalam proses respirasi lebih sedikit sehingga menyebabkan pertumbuhan tanaman menjadi lebih lambat. Penyemprotan PBZ pada beberapa penelitian dilakukan beberapa kali untuk mempertahankan tingkat peghambatan. Pada penelitian ini penyemprotan satu kali. Walaupun demikian penyemprotan PBZ pada 50 HST mampu menghambat pertumbuhan jumlah daun. Menurut Ningsih dan Dwi (2017), pemberian PBZ melalui daun lebih mudah, praktis, dan cepat namun jangka waktu pengaruhnya terhadap tanaman bersifat sementara, membutuhkan beberapa kali penyemprotan untuk mempertahankan tingkat penghambatan pertumbuhan.

\subsection{Kandungan Klorofil}

Hasil pengamatan daun trembesi setelah dianalisis ragam menunjukkan bahwa interaksi perlakuan waktu penyepotan dan konsentrasi PBZ berpengaruh terhadap kandungan klorofil relatif. Sedangkan perlakuan utama tidak berbeda nyata. Rata-rata pengamatan kandungan klorofil relatif setelah diuji lanjut $\mathrm{BNJ} \mathrm{p}<0,05$ dapat dilihat pada Tabel 5.

Kandungan Klorofil daun dengan satuan nilai Single Photon Avalanche Diode (SPAD) berbeda, baik antara individu maupun jenis yang diukur. Tabel 5 menunjukkan bahwa secara interaksi perlakuan yang tertinggi pada pengamatan kandungan klorofil adalah waktu penyemprotan hari ke 75 HST (W3) dan tanpa pemberian PBZ (K0) dengan nilai klorofil (46,80 SPAD) yang tidak berbeda nyata dengan kombinasi perlakuan lain kecuali pada perlakuan penyemprotan 75 HST dan konsentrasi PBZ 75 ppm (34,70 SPAD). Keragaman nilai pengamatan klorofil mengindikasi-kan bahwa kandungan klorofil relatif labil dan kurang respon terhadap perlakuan.
Umur daun berkaitan dengan kandungan klorofil dan plastisitas pembukaan stomata yang mana kedua faktor tersebut menentukan besarnya penyerapan $\mathrm{CO}_{2}$ (Hidayati et al. 2011). Namun demikian, jenis yang memiliki kandungan klorofil tinggi belum tentu memiliki kemampuan penyerapan $\mathrm{CO}_{2}$ juga tinggi, begitu pula sebaliknya. Ada beberapa faktor yang mempengaruhi hasil pengukuran kandungan klorofil menggunakan klorofil meter antara lain yaitu distribusi klorofil yang tidak merata pada daun akan membatasi kemampuan alat dalam menaksir klorofil secara in vivo (Monje dan Bugbes 1992), waktu penanaman serta rangkaian dan posisi daun yang akan mempengaruhi kehijauan suatu tanaman (Piekielek et al. 1997). Pengukuran kandungan klorofil juga dipengaruhi oleh ketebalan daun, karena kandungan klorofil yang terukur adalah per satuan luas.

\section{KESIMPULAN}

Pengaruh waktu dan konsentrasi PBZ terhadap pertumbuhan tanaman trembesi (Albizia saman Jacq.) secara interaksi memberikan pengaruh yang nyata dimana tingginya lebih rendah pada perlakukan. Pengaruh utama PBZ menyebabkan tanaman lebih rendah dari tanaman kontrol. Diameter batang trembesi semakin besar yang disemprot dengan PBZ dengan penyemprotan dan konsentasi PBZ yang lebih tinggi.

Ukuran diameter batang trembesi lebih besar pada sampel bibit trembesi perlakuan. Pembentukan cabang primer lebih sedikit pada sampel perlakuan. Demikian juga jumlah daun trembesi dengan pemberian konsentrasi PBZ telah menurunkan jumlah daun dibandingkan dengan kontrol. Semakin tinggi konsentrasi PBZ menghasilkan jumlah daun yang semakin rendah. Untuk kandungan klorofil menunjukkan keragaman tertinggi pada kontrol.

Tabel 5. Rata-rata Kandungan Klorofil Trembesi dengan Perlakuan Waktu Penyemprotan dan Konsentrasi PBZ.

\begin{tabular}{cccccc}
\hline Waktu & \multicolumn{3}{c}{ Konsentrasi Paclobutrazol (ppm) } & \multirow{2}{*}{ Rata-rata } \\
\cline { 2 - 5 } Penyempotan (HST) & $0(\mathrm{~K} 0)$ & $75(\mathrm{~K} 1)$ & $150(\mathrm{~K} 2)$ & $225(\mathrm{~K} 3)$ & \\
\hline $25(\mathrm{~W} 1)$ & $42,33 \mathrm{ab}$ & $37,40 \mathrm{ab}$ & $39,83 \mathrm{ab}$ & $39,73 \mathrm{ab}$ & 39,82 \\
$50(\mathrm{~W} 2)$ & $35,76 \mathrm{ab}$ & $41,20 \mathrm{ab}$ & $39,33 \mathrm{ab}$ & $36,93 \mathrm{ab}$ & 38,30 \\
$75(\mathrm{~W} 3)$ & $46,80 \mathrm{a}$ & $34,70 \mathrm{~b}$ & $36,33 \mathrm{ab}$ & $43,20 \mathrm{ab}$ & 40,25 \\
\hline Rata-rata & 41,63 & 37,76 & 38,49 & 39,95 & \\
\hline KK=4,47 \% & \multicolumn{5}{c}{ DMRT WK $=11,84$} \\
\hline
\end{tabular}

Keterangan : Angka-angka pada kolom dan baris yang diikuti oleh huruf kecil yang sama tidak berbeda nyata menurut uji beda nyata jujur $\mathrm{BNJ}$ pada $\mathrm{p}<0,05$. 


\section{UCAPAN TERIMA KASIH}

Ucapan terimakasih disampaikan kepada Universitas Islam Riau yang telah mendanai penelitian ini.

\section{DAFTAR PUSTAKA}

Ardigusa, Y., dan Dewi Sukma. 2015. Pengaruh paclobutrazol terhadap pertumbuhan dan perkembangan tanaman sanseviera (Sanseviera trifasciata Laurentii). Jurnal Hortikultura Indonesia 6 (1) : 45-53.

Bonaventura R.L, Semuel D. Runtunuwu, Johannes E.X. Rogi dan Pemmy Tumewu. 2014. Pengaruh waktu penyemprotan dan konsentrasi paclobutrazol (PBZ) terhadap pertumbuhan dan produksi tanaman jagung (Zea mays L.) Varietas Manado Kuning. Jurnal Cocos 1-9.

Direktorat Jenderal Pengendalian Perubahan Iklim, 2022. Kontribusi Penurunan Emisi GRK Nasional, Menuju NDC 2030. Diakses pada 21 Januari 2022. http://ditjen ppi.menlhk. go.id/berita-ppi/3150-kontribusi-penurunanemisi-grk-nasional,-menuju-ndc-2030.

Fathurrahman F., Nizam M.S., Wan Juliana W.A., Febri Doni, Nor Lailatul W.M. and Che Radziah C.M.Z. 2016. Effects of different $\mathrm{CO} 2$ concentration on growth and photosynthesic of rain tree plants (Albizia saman Jacq. Merr). AIP Conference Proceedings, 1784, 0200071- 0200075.; doi: 10.1063/1.4966717.

Hidayati N, M Reza, T Juhaeti dan M Mansur. 2011. Serapan karbondioksida $\left(\mathrm{CO}_{2}\right)$ jenis-jenis pohon di Taman Buah 'Mekar Sari' Bogor, kaitannya dengan potensi mitigasi gas rumah kaca. Jurnal Biologi Indonesia 7 (1) : 133-145.

Jungklang J., Saengni K. and J. Uthaibutra. 2017. Effects of water-deficit stress and paclobutrazol on growth, relative water content, electrolyte leakage, proline content and some antioxidant changes in Curcuma alismatifolia Gagnep. Saudi Journal of Biological Sciences 7 (24): 1505-1512.

Lattimer. 1998. Selecting and using plant growth regulators on floricultural crops. adapted from D. Bailey and B. Whipker. 1998. Height control of commercial greenhouse flowers. NC Coop. Ext. Serv. Horticulture Information Leaflet 528.

Monje, O.A. and Bugbes, B. 1992. Lnherent limitations of nondestructive chlorophyll meters : a comparison of two types of meters. J. Horti Science 27 (1) 69-71.

Nasrullah, N., Y.M. Wati dan D.W. Utami. 2012. Stimulasi pembungaan bugenvil (Bougenvillia spectabilis Willd) dengan retardan dan berbagai komposisimedia dalam lingkungan jalan yang terpolusi udara. Jurnal Lanskap Indonesia 4 (1): 65.

Ningsih, R. and R. Dwi. 2017. Application of paclobutrazol and micro inorganic fertilizer on the yield and seed quality of rice (Oryza sativa L.). Jurnal Agriprima 1(1): 22-34.

Piekielek, W., Lingenfelter, D. and Beegle, D. 1997. The early-seasan chlorophyll meter for corn. The Pennsylvania State Unrversity.

Rosmanita, B. 2008. Pengaruh paklobutrazol dan pupuk daun terhadap pertumbuhan dan perkembangan anggrek dendrobium 'Jiad Glold x Booncho Gold'. (Skripsi) Institut Pertanian Bogor. Bogor. 49 hal.

Runtunuwu, S. U., Rinny Mamarimbing, Pemmy Tumewu, dan Tommy Sondakh. 2011. Konsentrasi paclobutrazol dan pertumbuhan tinggi bibit cengkeh (Syzygium aromaticum (L.). Eugenia 17 (2) : 135-141.

Rugayah,1., Kus Hendarto, Yohannes, C., Ginting dan Rina Ristiani. 2020. Pengaruh konsentrasi paklobutrazol pada pertumbuhan dan penampilan tanaman sedap malam (Polyanthes tuberosa L.). Jurnal Agrotropika 19(1): 27-34.

Salisbury, F.B., dan C.W. Ross. 1995. Fisiologi Tumbuhan Jilid I. Edisi IV. ITB. Bandung.

Salisbury, F.B., and C.W. Ross. 1992. Fisiologi Tumbuhan Jilid 2. Terjemahan dari: FB Salisbury and CW Ross. Plant Physiology 4th Edition. Penerbit ITB Bandung. 173 hal.

Santiasrini, R. 2009. Pengaruh paklobutrazol terhadap pertumbuhan dan pembungaan gloksinia (Sinningia speciosa Pink). (Skripsi). Program Studi Hortikultura. Fakultas Petanian. Institut Pertanian Bogor. Bogor. 61 hal.

Tumewu, P., Paula Ch. Supit, Ridson B., Anni E. Tarore dan Selvie Tumbelaka. 2012. Pemupukan urea dan paclobutrazol terhadap pertumbuhan dan produksi tanaman jagung (Zea mays saccharata Sturt.) Jurnal Eugenia 18 (1): 39-48.

Widaryanto, E., M. Baskara., dan A. Suryanto. 2011. Aplikasi paklobutrazol pada tanaman bunga matahari (Helianthus Annuus L. Cv. Teddy Bear) sebagai upaya menciptakan tanaman hias pot. Perhorti Lembang. 6 hal. 